\title{
The veil of flor's structure, composition and interactions in biological ageing wines
}

\author{
M. Ruiz-Muñoz ${ }^{1}$, G. Cordero-Bueso ${ }^{1}$, S. Martínez ${ }^{2}$, F. Pérez ${ }^{3}$, D. Hughes-Herrera ${ }^{1}$, I. Izquierdo-Bueno ${ }^{1,4}$ y J.M. Cantoral $^{1}$ \\ ${ }^{1}$ Departamento de Biomedicina, Biotecnologíay Salud Pública, Universidad de Cádiz, Puerto Real, Cádiz, España \\ ${ }^{2}$ Emilio Lustau S.A. Jerezdela Frontera, Cádiz, España \\ ${ }^{3}$ Luis Caballero S.A. El Puerto de Santa María, Cádiz, España \\ ${ }^{4}$ Departamento de Química Orgánica, Universidadde Cádiz, Puerto Real, Cádiz, España
}

\begin{abstract}
Biological ageing occurs after fermentation of the grape must and it is due to the appearance of a biofilm on the surface of the wine called "veil of flor". Yeast involved in veil formation are mainly Saccharomyces cerevisiae and they have traditionally been divided into four races according to their ability to metabolize different sugars. The growth of flor yeasts depends on different factors, such as the aerobic assimilation of the wine ethanol, since the medium is deficient in both sugars and nitrogen. Actually, flor yeast metabolism is different from wine $S$. cerevisiae yeast, but it hasn't been analysed yet. Thus, the aim of this work is to study the diversity of flor yeast strains and to analyse the composition and the structure of the veil of flor in Jerez-Xérés-Sherry D.O. The results of this work revealed 14 different genotypes of S. cerevisiae strains using multiplex-microsatellite PCR and these strains showed 8 different biochemical profiles using a similar procedure than traditionally. In addition, mannose and glucose were found in veil of flor complex using UHPLC-MS.
\end{abstract}

\section{Introducción}

La crianza biológica es un proceso que se caracteriza por la formación de una biopelícula en la superficie del vino conocida como "velo de flor" [1]. Este proceso comienza después de la fermentación alcohólica del mosto, donde se obtiene un vino inicial que se conoce como "vino base". El velo de flor está formado mayoritariamente por levaduras pertenecientes a la especie $S$. cerevisiae. Estas llevan a cabo una oxidación progresiva del alcohol presente en el vino base y los carbohidratos que no se hayan consumido durante la fermentación. Se trata de un proceso lento y muy sensible, y gracias al metabolismo oxidativo de las levaduras de velo de flor se obtienen diversos compuestos aromáticos que contribuyen a las características organolépticas distintivas de estos vinos. La crianza biológica se lleva a cabo de forma tradicional en diversas regiones de Europa, incluidas Hungría, Italia, Francia y el sur de España, más concretamente en Córdoba (en la Denominación de Origen "Montilla- Moriles") y Cádiz (en la Denominación de Origen "Jerez- XèrésSherry") $[2,3]$.

En el caso del vino Fino (D.O. Jerez-Xèrés-Sherry), el vino base se obtiene gracias a la fermentación espontánea de mosto de Vitis vinifiera var. Palomino Fino y este entra en el sistema dinámico de crianza biológica de "criaderas y soleras", teniendo un tiempo mínimo de 3 años de crianza [3]. El sistema consiste en una serie de barriles de roble americano de 500 litros de capacidad que contienen vino en diferentes fases de maduración. En la primera fase, conocida como "sobretablas", el vino base alcanza $15 \%(\mathrm{v} / \mathrm{v})$ de etanol debido a la adición etanol vínico (lo que se conoce como "encabezado").
Las etapas intermedias se denominan "criaderas" y la última fase, denominada "solera", es donde se encuentra el producto completamente terminado. Únicamente puede extraerse una tercera parte del vino que se encuentre en los barriles de "solera", transfiriéndose el mismo volumen desde las fases anteriores, denominándose "sacas" y "rocíos" [3].

Tradicionalmente, las levaduras de velo de flor se diferenciaron atendiendo a su capacidad para metabolizar diferentes azúcares (glucosa, galactosa, sacarosa, lactosa, maltosa, melibiosa y rafinosa), clasificándose en cuatro variedades o razas: $S$. cerevisiae var. beticus, $S$. cerevisiae var. cheresiensis, $S$. cerevisiae var. montuliensis y S. cerevisiae var. rouxii [4]. Sin embargo, según estudios taxonómicos posteriores [5], la raza montuliensis se reclasificó como Torulaspora delbrueckii, mientras que la raza rouxii se catalogó como Zygosaccharomyces rouxii. Sin embargo, son pocos los estudios que han empleado las técnicas de biología molecular basadas en PCR para estudiar más a fondo la diversidad de levaduras presentes en el velo de flor $[6,7]$.

Se sabe que la capacidad de $S$. cerevisiae para adaptarse a las condiciones de crianza biológica depende de la activación de ciertas rutas metabólicas [2]. Aunque se han identificado algunos genes implicados en estas rutas [6], aún no se conocen con exactitud las interacciones establecidas entre las levaduras durante la crianza biológica. Como paso previo al estudio de dichas interacciones, es necesario explorar y conocer los diferentes genotipos de $S$. cerevisiae presentes en el velo de flor. Así, como principal objetivo de este trabajo se plantea estudiar la diversidad de levaduras de velo de flor en vinos bajo crianza biológica y conocer la composición y

(C) The Authors, published by EDP Sciences. This is an Open Access article distributed under the terms of the Creative Commons Attribution License 4.0 (http://creativecommons.org/licenses/by/4.0/). 
la estructura de dichos velos en bodegas diferentes situadas en la D.O. Jerez-Xèrés-Sherry.

\section{Material y métodos}

Las muestras de velo de flor analizadas en este trabajo se obtuvieron de un total de 60 botas de vino Fino distribuidas en tres bodegas distintas de El Puerto de Santa María y Jerez de la Frontera (Cádiz). Dichas botas se muestrearon una vez al mes durante un año completo. Para la toma de muestra, se empleó una venencia modificada capaz de recoger velo, lavando con etanol al $70 \%$ antes y después de cada recogida.

En primer lugar, se aislaron y seleccionaron las colonias de levaduras que se consideraron distintas, empleando como medio de cultivo YPD (2\% glucosa, $2 \%$ peptona, $1 \%$ extracto de levadura, $2 \%$ agar) y como método de conservación glicerol al $40 \%$ a una temperatura de $-40{ }^{\circ} \mathrm{C}$.

La identificación de los aislados se llevó a cabo empleando técnicas de biología molecular basadas en PCR. Más concretamente, se llevó a cabo la amplificación de la región 5.8S-ITS, se secuenció y se digirió con las endonucleasas de restricción HaeIII, HinfI y CfoI tal y como describieron previamente [7]. Además, las colonias identificadas como $S$. cerevisiae se analizaron a nivel de cepa mediante la amplificación simultánea de tres loci con alta densidad de microsatélites (SSR multiplex) tal y como describieron [8]. En ambos casos, los resultados se observaron mediante gel de agarosa al $2.5 \%$ en TBE 1X, empleando como marcador de pesos moleculares HyperLadder II (Bioline). Los resultados se observaron mediante el empleo de bromuro de etidio y de un transiluminador UV (Bio-Rad).

Las levaduras que mostraron patrones genéticos distintos se caracterizaron mediante pruebas de fermentación de ciertos azúcares (glucosa, sacarosa, fructosa, lactosa, maltosa y rafinosa) y de asimilación de distintas fuentes de carbono y nitrógeno (glucosa, almidón, melibiosa, inulina, citrato de amonio, nitrito y urea). Para ello, se emplearon placas de 96 pocillos de poliestireno y un lector de placas para medir la densidad óptica de los cultivos a $610 \mathrm{~nm}$ durante 72 horas, incubando a $28^{\circ} \mathrm{C}$ [9]. Todas las pruebas se realizaron por triplicado, considerando como positivo si se producía un aumento de la densidad óptica en más de 0.4 .

Por otro lado, se obtuvieron imágenes detalladas de los velos de flor analizados mediante microscopía electrónica de barrido empleando el microscopio FEI Quanta 200. Para ello, las muestras se colocaron sobre un cubre con poli-Llisina y se fijaron con glutaraldehído al $2.5 \%$ en cacodilato sódico $0.1 \mathrm{M}$, deshidratando la muestra con acetona $\mathrm{y}$ metalizando con oro.

Por último, se analizaron los monosacáridos mayoritarios que intervienen en la conformación del velo de flor empleando cromatografía líquida de ultra alta presión acoplada a espectrometría de masas (UHPLC-MS/MS) empleando una columna Illic. Para poder disgregar la estructura del velo y poder analizarlo correctamente, las muestras se sometieron a sonicación. Las muestras se concentraron y posteriormente se disolvieron en agua ultra pura, filtrándolas con filtros de $0.2 \mu \mathrm{m}$. Se prepararon diluciones a una concentración de 1 y 10 ppm y se analizaron mediante UHPLC-MS.

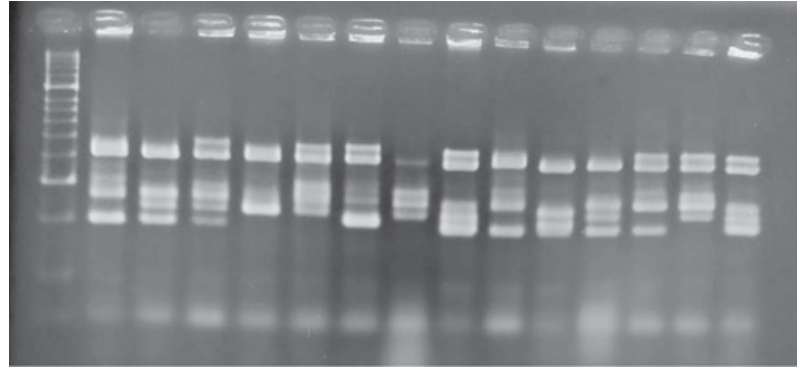

Figura 1. Patrones de bandas obtenidos a partir del análisis del polimorfismo de tres regiones de microsatélites. Gel de agarosa al 2.5\%, el marcador de peso molecular es HyperLadder II (Bioline).

\section{Resultados y discusión}

En total, se han analizado 15.000 colonias de levaduras procedentes de 60 botas distintas ubicadas en tres bodegas de la D.O. Jerez-Xèrés-Sherry durante un año completo. Mediante el análisis de la región ITS se han identificado 5 especies pertenecientes a 3 géneros distintos. La especie mayoritaria fue Saccharomyces cerevisiae (95\% del total) por lo que se analizaron tres regiones de microsatélites distintas (SCPTSY7, SCYOR267C, SC8132X) con alto grado de polimorfismo para poder identificar a nivel de cepa.

De esta forma, se obtuvieron 14 patrones distintos, denominándolos desde FI a F14. (Fig. 1).

Las diferentes cepas de $S$. cerevisiae obtenidas gracias al análisis de microsatélites fueron caracterizadas atendiendo a su capacidad para fermentar azúcares y asimilar diferentes fuentes de carbono y nitrógeno, considerando positivo si la densidad óptica era mayor que 0.4 después de 72 horas de incubación a $28^{\circ} \mathrm{C}$ (Tabla 1 ).

Así, se han obtenido 9 perfiles distintos según las pruebas bioquímicas, ya algunas de las levaduras analizadas han mostrado las mismas características bioquímicas a pesar de ter un patrón molecular distinto. Este es el caso de los patrones F1 y F6, de los patrones F2 y F3 y de F5, F7, F9, F12 y F13.

Estos resultados muestran una alta variabilidad tanto en la identificación genética como en la caracterización bioquímica. A nivel genético, se han obtenido 14 cepas distintas pertenecientes a la especie $S$. cerevisiae, mientras que en otros estudios similares realizados en la D.O. Montilla-Moriles (Córdoba) únicamente se han descrito 4 patrones distintos empleando las mismas regiones de microsatélites [10].

Por otro lado, se han identificado 8 perfiles distintos atendiendo a la capacidad de fermentar ciertos azúcares y de asimilar diferentes fuentes de carbono y nitrógeno. Sin embargo, otros estudios realizados sobre el velo de flor $[1,4,11]$, habían descrito 4 perfiles distintos empleando las mismas pruebas bioquímicas que en el presente trabajo, dando lugar a la clasificación tradicional de las levaduras de velo de flor, resultando en 4 razas en función de sus características morfológicas y sus propiedades fisiológicas (beticus, cheresiensis, montuliensis y rouxii).

Se obtuvieron imágenes de microscopía electrónica de barrido de 4 muestras distintas de velo de flor, observando la adhesión entre las células de levadura que permite que se establezca y estabilice la estructura (Fig. 2). No 
Tabla 1. Resultados de la fermentación de diferentes azúcares y la asimilación de diferentes fuentes de carbono y nitrógeno, donde "+" indica "positivo" mientras que "-" significa "negativo".

\begin{tabular}{|c|c|c|c|c|c|c|c|c|c|c|c|c|c|c|c|}
\hline & Fl & $\mathrm{F} 2$ & F3 & F4 & F5 & F6 & F7 & F8 & F9 & F10 & F11 & F12 & F13 & F14 \\
\hline \multirow{6}{*}{ 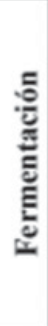 } & Glucosa & + & + & + & + & + & + & + & + & + & + & + & + & + & + \\
\hline & Fructosa & + & + & + & + & + & + & + & + & + & + & + & + & + & + \\
\hline & Sacarosa & + & + & + & + & + & + & + & + & + & + & + & + & + & + \\
\hline & Maltosa & + & - & - & + & - & + & - & - & - & + & - & - & - & - \\
\hline & Lactosa & - & - & - & - & - & - & - & - & - & - & - & - & - & - \\
\hline & Rafinosa & + & + & + & + & + & + & + & - & + & + & + & + & + & - \\
\hline \multirow{7}{*}{ 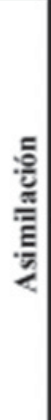 } & Glucosa & + & - & - & + & + & + & + & - & + & + & + & + & + & + \\
\hline & Almidón & - & - & - & + & - & - & - & - & - & - & - & - & - & - \\
\hline & Melibiosa & - & - & - & + & - & - & - & - & - & + & - & - & - & - \\
\hline & Inulina & - & - & - & - & - & - & - & - & - & - & + & - & - & - \\
\hline & Citrato & + & - & - & + & + & + & + & + & + & + & + & + & + & + \\
\hline & Nitrito & - & - & - & + & - & - & - & - & - & - & - & - & - & - \\
\hline & Urea & + & - & - & + & + & + & + & - & + & + & + & + & + & + \\
\hline
\end{tabular}

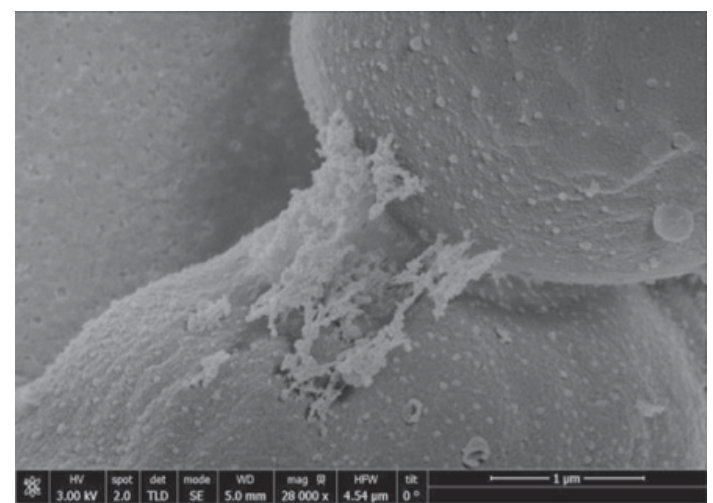

Figura 2. Fotografía de microscopía electrónica (FEI Quanta 200) de dos levaduras de velo de flor.

se apreciaron diferencias significativas en las uniones observadas en las muestras analizadas.

Para identificar las moléculas presentes en el biofilm generado por las levaduras de velo de flor, se están analizando dos muestras procedentes de dos fases distintas dentro del sistema de "criaderas y soleras" mediante UHPLC-MS. Hasta ahora, se ha determinado la presencia de residuos de manosa y glucosa, monosacáridos cuya presencia ya se había descrito en matrices extracelulares generadas por $S$. cerevisiae [12] y otras especies de levaduras formadoras de velo [14, 15]. Actualmente se están analizando el resto de señales detectadas en los cromatogramas y espectros obtenidos, pudiéndose identificar otros compuestos que formen parte de la estructura del velo de flor.

Este trabajo ha sido financiado por CDTI IDI20180007. Agradecemos a las bodegas Luis Caballero S.A. and Emilio Lustau S.A. por su participación y apoyo en dicha investigación.

\section{Referencias}

[1] B. Esteve-Zarzoso, M.J. Peris-Torán, E. GarcíaMaiquez, F. Uruburu, A. Querol, Appl. Environ. Microbiol. 67 (2001)

[2] J.L. Legras, J. Moreno-Garcia, S. Zara, G. Zara, T. Garcia-Martinez, J.C. Mauricio, I. Mannazzu, A.L. Coi, M.B. Zeidan, S. Dequin, J. Moreno, M. Budroni, Front. Microbiol. 7, 5 (2016)

[3] G. Cordero-bueso, M. Ruiz-muñoz, M. González Moreno, S. Chirino, M. Del, C. Bernal-Grande, J.M. Cantoral, Ferment. 4, 1 (2018)

[4] P. Martínez, L. Pérez Rodríguez, T. Benítez, Am. J. Enol. Vitic. 48, 1 (1997)

[5] B. Kurtzman, C.P. Fell, J.W. Yeasts, Taxonomic Study, 5th ed. (2015)

[6] G. Zara, P. Goffrini, T. Lodi, S. Zara, I. Mannazzu, M. Budroni, FEMS Yeast Res. 12, 7 (2012)

[7] B. Esteve-Zarzoso, M.T. Fernández-Espinar, A. Querol, A. van Leeuwenhoek, Int. J. Gen. Mol. Microbiol. 85, 2 (2004)

[8] E. Vaudano, E. Garcia-Moruno, Food Microbiol. 25, 1 (2008)

[9] M. Ruíz-Muñoz, M. Bernal-Grande, G. CorderoBueso, M. González, D. Hughes-Herrera, J. Cantoral, Ferment. 3, 4 (2017)

[10] M. Marin-Menguiano, S. Romero-Sanchez, R.R. Barrales, J.I. Ibeas, Int. J. Food Microbiol. 244 (2017)

[11] P. Martínez, M.J. Valcárcel, L. Pérez, T. Benítez, Am. J. Enol. Vitic. 49, 3 (1998)

[12] F. Faria-Oliveira, J. Carvalho, C.L.R. Belmiro, G. Ramalho, M. Pavão, C. Lucas, C. Ferreira, J. Basic Microbiol. 55, 6 (2015)

[13] C. Lucas, C. Ferreira, J. Carvalho, F. Faria-Oliveira, M. Pavão, C. Gil, M.L. Hernaez, C.L. Belmiro, M. Martinez-Gomariz, BMC Microbiol. 14, 1 (2014)

[14] P. Lal, D. Sharma, P. Pruthi, V. Pruthi, J. Appl. Microbiol. 109, 1 (2010) 